\title{
Anti-Inflammatory Effects of Physical Exercise on Obesity
}

\section{Lídia Figueiredo1, Ramiro Barcos Nunes ${ }^{2,3}$, Bruna Marmett ${ }^{4}$, Larissa Bianca Paiva Cunha de Sá1, Alberto Krayyem Arbex ${ }^{1,5}$}

\author{
${ }^{1}$ Division of Endocrinology, IPEMED Medical School, São Paulo, Brazil \\ ${ }^{2}$ Laboratory of Experimental Physiology, Universidade Federal de Ciências da Saúde de Porto Alegre, Porto Alegre, Brazil \\ ${ }^{3}$ Research Department, Instituto Federal Sul-Rio-Grandense, Gravataí, Brazil \\ ${ }^{4}$ Laboratory of Air Pollution, Universidade Federal de Ciências da Saúde de Porto Alegre, Porto Alegre, Brazil \\ ${ }^{5}$ Diabetology Department, Malteser Krankenhaus St. Franziskus-Hospital, Flensburg, Germany \\ Email: ramiro.barcos@gmail.com, brumarmett@hotmail.com, lbpcs@gmail.com, albertoarbex@gmail.com
}

How to cite this paper: Figueiredo, L., Nunes, R.B., Marmett, B., de Sá, L.B.P.C. and Arbex, A.K. (2017) Anti-Inflammatory Effects of Physical Exercise on Obesity. Open Journal of Endocrine and Metabolic Diseases, 7, 44-51.

http://dx.doi.org/10.4236/ojemd.2017.71005

Received: November 8, 2016

Accepted: January 3, 2017

Published: January 6, 2017

Copyright $\odot 2017$ by authors and Scientific Research Publishing Inc. This work is licensed under the Creative Commons Attribution International License (CC BY 4.0).

http://creativecommons.org/licenses/by/4.0/

\begin{abstract}
Obesity is a disease of epidemic proportions, associated with chronic inflammation in response to increased secretion of inflammatory cytokines originating in adipose tissue. Exercise has been shown to be effective in combating these changes. The aim of this study was to review the anti-inflammatory effect of physical exercise in the pathogenesis of obesity. We conducted a search of the terms "exercise", "obesity" and "inflammation" on Medline and PubMed databases, restricting results to clinical trials published since 2011. The retrieved studies showed that physical exercise could, via different pathways, reduce levels of CRP, IL- 6 and TNF- $\alpha$, as well as other proinflammatory markers. Additionally, exercise was able to increase expression of genes related to the production of nitric oxide, positively modulating endothelial function and chronic inflammation in obese patients, with or without caloric restriction. In conclusion, aerobic exercise of moderate intensity is an effective intervention strategy for chronic inflammation associated with obesity.
\end{abstract}

\section{Keywords}

Cardiovascular Disease, Atherosclerosis, Metabolic Syndrome X, Weight Loss

\section{Introduction}

Obesity is a chronic disease characterized by an excess of adipose tissue, which affects 600 million people worldwide [1]. According to the same report, nearly two billion people are classified as overweight, which negatively affects public health expenditures, due to an increase in associated diseases [2]. The strong 
correlation between excess adipose tissue and a higher incidence of arterial hypertension, stroke, dyslipidemia, atherosclerosis, type 2 diabetes and other cardiovascular complications suggests that obesity could exert a negative influence on population health [2] [3].

For decades, the unique function assigned to adipocytes was energy storage via triglycerides. Over the years, this simplistic point of view has been studied and it is now known that this tissue is able to synthesize substances that regulate vascular tone and hemostasis, beyond its additional essential functions to the organism [3] [4]. The literature has indicated the proinflammatory action of adipocytokines in mechanisms of vascular injury, insulin resistance and endothelial dysfunction, which accelerate and increase the appearance of atherosclerosis [5] [6]. The authors highlight tumor necrosis factor alpha (TNF- $\alpha$ ), interleukin-6 (IL-6) and C-reactive protein (CRP) as key markers of inflammatory response [4] [5] [6].

Physical exercise, however, has been considered a safe and effective method with which to manage alterations that are exacerbated by obesity [6]. Studies demonstrate the possibility to improve inflammatory profile, hemostasis, endothelial function, insulin sensitivity and antioxidant activity in subjects with vascular commitment when submitted to different training strategies [7] [8] [9]. Considering the interrelationship between obesity, chronic inflammation and exercise, the aim of this study was to review the literature concerning the antiinflammatory effect of physical exercise in the pathogenesis of obesity.

\section{Methodology}

A search identifying studies to include in this review was performed on the electronic databases Medline and PubMed using the keywords "exercise", "obesity" and "inflammation". The search was restricted to clinical trials conducted in humans, published between 2011 and 2016, and written in English. The strategy of research follows: "obesity AND inflammation (tiab) AND exercise (tiab) AND (ClinicalTrial AND 2011/03/23: 2016/03/20 AND humans)”. Articles selected were analyzed by reading the full text to identify the main outcomes of the studies. A flow diagram of the selection process is in Figure 1. Additional information was obtained from review articles relevant to the topic. The information of articles selected is described in Table 1.

\section{Discussion}

Chronic inflammation is considered to be an independent risk factor for several clinical conditions [6]. Adipose tissue possesses the ability to secrete proinflammatory cytokines, which damage vascular function in different pathways. Coelho and colleagues [4] demonstrated that hypertrophy of adipose cells increases macrophage mobility, leading to the expression of TNF- $\alpha$ and IL-6, which in turn reduces the bioavailability of nitric oxide (NO) and, consequently, the capacity of vasodilatation. Reduced levels of adiponectin promote mutation of macrophages into foam cells, however, implying involvement in the formation of 

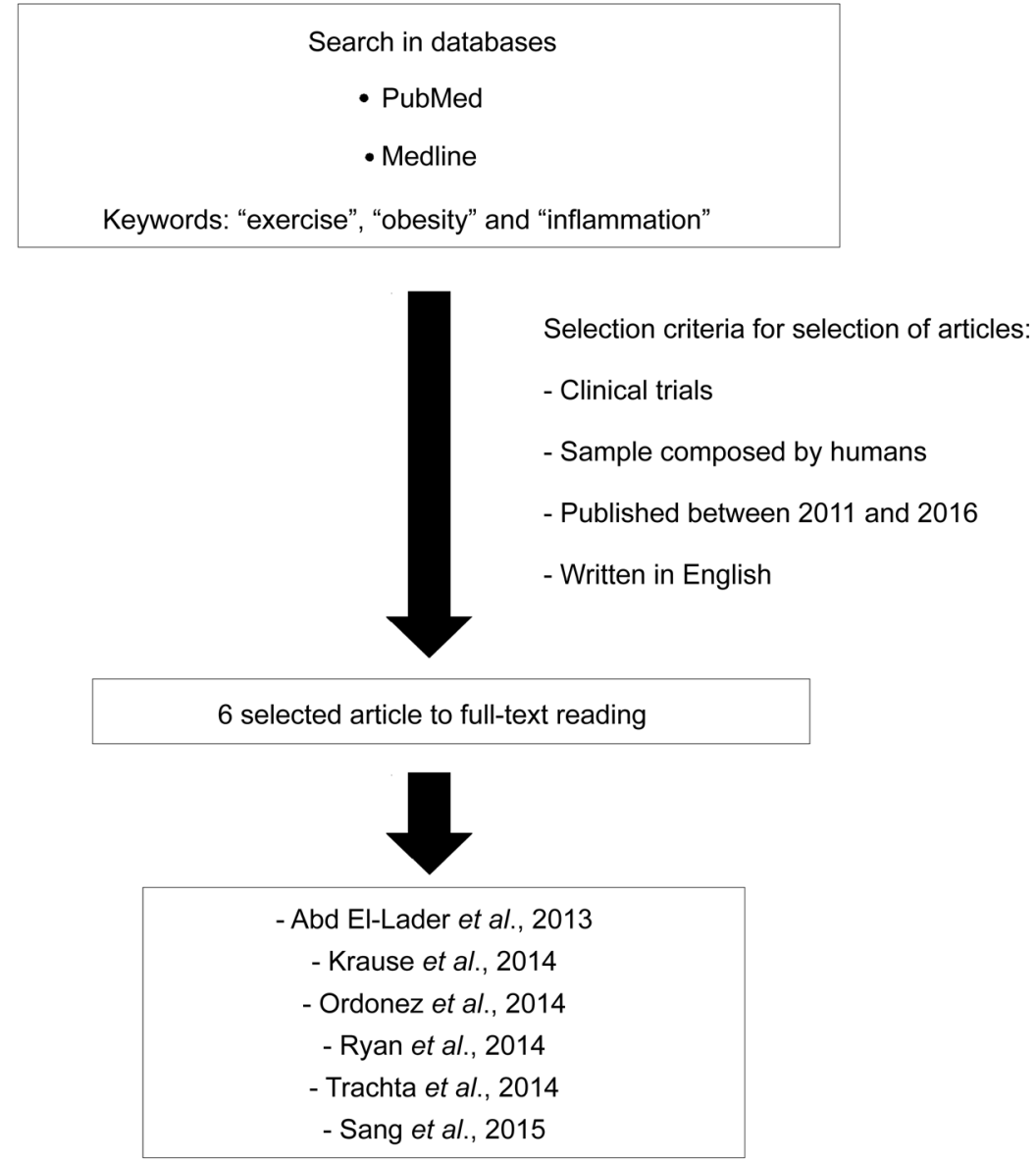

Figure 1. Selection process of the articles.

atherosclerotic plaques [5]. Moreover, a higher concentration of resistin increases release of endothelin-1 (ET-1), stimulating vasoconstriction [4] [5]. These various mechanisms act synergistically to potentiate inflammation in the vessel.

Recently, a review by Fiuza-Luces and colleagues [7] demonstrated the benefits of physical exercise in health promotion. This article showed that physical training is capable of positively modulating mitochondrial biogenesis, fatty acid oxidation, insulin sensitivity, endothelial function and other relevant factors essential to organism function. Similarly, several studies have shown the benefits of physical exercise in ameliorating chronic inflammation associated with obesity [9] [10] [11] [12], endorsing the guidelines that assist prescription in treatment of this syndrome [13].

In view of elucidating the role of physical exercise in inflammation, Abd El-Kader and colleagues [8] investigated the impact of aerobic training performed in two different intensities on inflammatory profile in obese patients with type 2 diabetes. One group of 25 subjects underwent three months of low intensity aerobic training $\left(55 \%-65 \%\right.$ of the maximum heart rate, $\left.\mathrm{HR}_{\mathrm{MAX}}\right)$ and the other group of 25 subjects underwent moderate intensity training $(65 \%$ $\left.75 \% \mathrm{HR}_{\mathrm{MAX}}\right)$. At the end of the experimental period, both methodologies proved 
Table 1. Articles selected to review and its main results.

\begin{tabular}{|c|c|c|c|}
\hline Author/year & Sample characteristics (n) & Intervention & Main outcome \\
\hline $\begin{array}{l}\text { Abd El-Kader } \\
\text { et al., } 2013\end{array}$ & $\begin{array}{l}\text { Obese type } 2 \text { diabetic patients } \\
\mathrm{n}=50\end{array}$ & $\begin{array}{l}\text { Moderate and mild aerobic exercise } \\
\text { training, three times/week for } 3 \text { months. }\end{array}$ & $\begin{array}{l}\downarrow \text { Leptin, TNF- } \alpha \text {, IL2, IL4, IL6, HOMA-IR and } \\
\text { HBA1c }\end{array}$ \\
\hline $\begin{array}{l}\text { Krause et al., } \\
\quad 2014\end{array}$ & $\begin{array}{l}\text { Male adults sedentary with } \\
\text { obesity and type } 2 \mathrm{DM} \mathrm{n}=25\end{array}$ & $\begin{array}{l}\text { Low or moderate intensity exercise for } \\
30 \mathrm{~min} \text {, three times per week. }\end{array}$ & $\begin{array}{l}\uparrow \text { M uscle nNOS and tNOx in controls } \\
\uparrow \text { Plasma catalase increased in T2DM } \\
\text { No differences in plasma inflammatory markers }\end{array}$ \\
\hline $\begin{array}{l}\text { Ordonez et al., } \\
\qquad 2014\end{array}$ & $\begin{array}{l}\text { Premenopausal obese young } \\
\text { women with Down syndrome } \\
\mathrm{n}=20\end{array}$ & $\begin{array}{l}\text { Aerobic training, three sessions per } \\
\text { week for } 10 \text {-week with a work } \\
\text { intensity of } 55 \%-65 \% \text { of peak heart rate. }\end{array}$ & $\begin{array}{l}\downarrow \text { TNF- } \alpha \text {, IL- } 6 \text { and high sensitive CRP in plasma } \\
\downarrow \text { Percentage of fat }\end{array}$ \\
\hline $\begin{array}{l}\text { Ryan et al., } \\
\quad 2014\end{array}$ & $\begin{array}{l}\text { Overweight and obese } \\
\text { sedentary postmenopausal } \\
\text { women } \mathrm{n}=77\end{array}$ & $\begin{array}{l}\text { Aerobic exercise training } 3 \text { days a } \\
\text { week for six months. }\end{array}$ & $\begin{array}{l}\downarrow \text { ICAM - } 1 \text { mRNA expression } \\
\uparrow \text { VCAM - } 1 \text {, HDL-c, VO2MAX } \\
\downarrow \text { Fat mass, visceral fat, triglycerides, insulin } \\
\text { resistance, waist circumference and CRP }\end{array}$ \\
\hline $\begin{array}{l}\text { Trachta et al., } \\
2014\end{array}$ & $\begin{array}{l}\text { Obese women with arterial } \\
\text { hypertension } n=15\end{array}$ & $\begin{array}{l}\text { Aerobic exercise for } 30 \mathrm{~min}, 3 \text { times a } \\
\text { week for three-month }\end{array}$ & $\begin{array}{l}\text { No changes in TC, LDL-C, HDL-C and triglycerides, } \\
\text { leptin, insulin and adiponectin concentrations } \\
\uparrow \text { In insulin sensitivity, HOM A-IR } \\
\downarrow \text { PCR }\end{array}$ \\
\hline $\begin{array}{l}\text { Sang et al., } \\
\quad 2015\end{array}$ & $\begin{array}{l}\text { Patients with Metabolic } \\
\text { Syndrome } \mathrm{n}=39\end{array}$ & $\begin{array}{l}\text { Walk/run training program } 5 \text { times a } \\
\text { week for } 10 \text { week }\end{array}$ & $\begin{array}{l}\text { No changes TC, LDL-C, HDL-C and triglycerides } \\
\downarrow \text { MDA, PON } 1 \\
\uparrow \text { Sub-fraction of HDL-c }\end{array}$ \\
\hline
\end{tabular}

CRP: C-reactive protein; DM: diabetes mellitus; HBAlc: glycated hemoglobin; HDL-c: high-density lipoprotein c; HOMA-IR: homeostasis model assessment-insulin resistance; IL2: interleukin-2; IL4: interleukin-4; IL6: interleukin-6; LDL-c: low-density lipoprotein c; MDA: malondialdehyde; PON1: paraoxonase-1; TC: total cholesterol; TNF- $\alpha$ : tumor necrosis factor alpha; tNOx: nitric oxide metabolites.

to be beneficial in reduction of leptin, PCR, IL- 6 and TNF- $\alpha$ levels. Patients who underwent the more intensive strategy demonstrated greater reductions in the parameters analyzed, however, suggesting that more intense training leads to a greater reduction of chronic inflammation in obese patients. Abd El-Kader and colleagues [8] attributed the subclinical improvement of the patients to the suppression of inflammatory cytokines and greater production of anti-inflammatory cytokines mediated by muscle action, given that visceral fat was not assessed in the study. Fiuza-Luces and colleagues [7] corroborated the results of Abd El-Kader and colleagues, demonstrating that the ability to secrete anti-inflammatory substances, such as IL-10, increases with skeletal muscle contraction. In this way, a more intense activity could produce a greater quantity of such metabolites.

In contrast, Krause and colleagues [14] did not find the same results after 16 weeks of low intensity $\left(30 \%-40 \% \mathrm{VO}_{2 \mathrm{MAX}}\right)$ and moderate intensity (55\% - 65\% $\mathrm{VO}_{2 \mathrm{MAX}}$ ) aerobic exercise. The author noticed, however, that obese subjects with type 2 diabetes possessed reduced levels of protein carbonyls, a marker of oxidative stress, and increased antioxidant activity of catalase. Additionally, the same group showed higher expression of the neuronal nitric oxide synthesis (nNOS) gene, suggesting higher production of NO. These findings support the hypothesis that moderate intensity aerobic training is more effective in modulating endothelial function in obese patients with already present vascular abnormalities. According to Fiuza-Luces and colleagues [7], metabolic stimulus provided by exercise could trigger a sequence of events, including increases in gene tran- 
scription linked to mitochondrial biogenesis (e.g., PCG-1 $\alpha$ ) and fatty acid oxidation (e.g., FAT/CD36), as well as inhibiting genes connected to cholesterol synthesis (e.g., HMGR).

Ordonez and colleagues [10] evaluated effects of 10 weeks of aerobic training on the inflammatory profile of obese women with Down syndrome. The training program began with thirty minutes on a treadmill, with intensity corresponding to $55 \%$ of $\mathrm{HR}_{\mathrm{MAX}}$, three times per week. Every two weeks, time and intensity were increased by two minutes and $2.5 \%$ of $\mathrm{HR}_{\mathrm{MAX}}$. After the intervention period, decreases in plasmatic levels of PCR $(0.62 \pm 0.11 \mathrm{vs} 0.53 \pm 0.09 \mathrm{mg} / \mathrm{dl})$, IL-6 $(8.2 \pm 1.1$ vs $6.1 \pm 0.9 \mathrm{pg} / \mathrm{ml})$ and TNF- $\alpha(11.7 \pm 1.6 \mathrm{vs} 9.2 \pm 1.3 \mathrm{pg} / \mathrm{ml})$ were observed, as well as a reduction in percentage of fat ( $38.9 \pm 4.0$ vs $35.0 \pm 3.8 \%)$. Rodriguez-Hernandez and colleagues [3] showed that these markers are closely connected to a higher uptake of low-density lipoprotein c (LDL-c) from endothelial cells and expression of intercellular adhesion molecule 1 (ICAM-1), vascular cell adhesion molecule 1 (VCAM-1) and monocyte chemoattractant protein-1 (MCP-1), which are vascular inflammation markers involved in atherosclerosis. Decreases in the concentration of these markers therefore indicate lower vascular inflammation.

Recently, Ryan and colleagues [9] investigated effects of six months of aerobic training on weight loss and systemic and vascular inflammation in obese postmenopausal women. Participants were randomized into two groups, treatment and control. Both groups underwent caloric restriction of 300 to $500 \mathrm{kcal} /$ day in order to minimize interference of diet [13]. The treatment group performed aerobic exercise on a treadmill or elliptical three times a week, at between 50\% and $60 \%$ of heart rate reserve (HRR), gradually progressing to $85 \%$. Sessions consisted of 30 to 45 minutes in the target zone of intensity. The main outcome observed was a decrease in ICAM-1 mRNA expression, indicating lower intracellular adhesion, and increased VCAM-1, suggesting increased vascular involvement. The authors could not explain the increase of this inflammatory biomarker. Additional variables, such as fat mass, visceral fat, triglycerides, insulin resistance, waist circumference and CRP, showed a similar reduction in both groups. Only the treatment group, however, showed a significant increase in $\mathrm{VO}_{2 \mathrm{MAX}}$ and high-density lipoprotein $\mathrm{c}$ (HDL-c) levels. The authors therefore concluded that systemic inflammation may be ameliorated independently from exercise, instead being related to a decrease of fat mass and improvement of insulin sensitivity. There is, however, no evidence that lifestyle, consisting of the combination of diet and exercise, may alter biomarkers related to endothelial dysfunction in postmenopausal obese women.

In a similar vein, Trachta and colleagues [12] evaluated anthropometric, biochemical and hormonal parameters in obese subjects after three months of aerobic training. Obese and hypertensive women performed 30 minutes of aerobic exercise, three times a week, and were compared to healthy subjects. Contrary to initial expectations, there were no changes in lipid profile (TC, LDL-C, HDL-C and triglycerides), leptin, insulin and adiponectin concentrations, even when 
comparing obese and healthy subjects at baseline. An improvement in insulin sensitivity was observed, however, via homeostasis model assessment-insulin resistance (HOMA-IR) and systemic inflammation, assessed by PCR. Interestingly, expression of genes related to subcutaneous adipose tissue, such as apelin, adiponectin and signal transducer activator of transcription 3 (STAT3), were elevated in obese subjects with hypertension before the intervention and were not sensitive to the treatment. The exception was a greater expression of the aquaporin-3 gene, suggesting that there may be alterations in the proliferative capacity of adipose tissue after performing exercise. This study was the first to investigate this gene, so more studies should be conducted to obtain a better understanding of its involvement. In summary, expression of genes in adipose tissue does not appear to be affected by physical activity, with the exception of aquaporin-3, indicating that endocrine function of this tissue is not improving insulin sensitivity and systemic inflammation. Related to this hypothesis, Wang and Nakayama [15] reported that visceral adipose tissue secretes greater amounts of cytokines than does the subcutaneous portion. The absence of expected effects in the study by Trachta and colleagues [12] may therefore be due to usage of samples extracted subcutaneously.

In addition, Sang and colleagues [11] investigated whether or not aerobic exercise affects the anti-inflammatory capacity of patients with metabolic syndrome (MS). Patients with MS were randomized into two groups: one underwent a training program and the other remained in an untrained state. All sessions were supervised and consisted of periods of intercalated running and walking. The duration of each session was gradually increased from 30 to $60 \mathrm{~min}$ and intensity was set at $60 \%-70 \%$ of $\mathrm{HR}_{\mathrm{MAX}}$. There was no caloric restriction over the 10 weeks of intervention. In accordance with other studies, there were no changes in the lipid profile (TC, LDL-C, HDL-C and triglycerides); however, subjects in the intervention group showed a reduction in oxidative stress, due to a decrease in malondialdehyde (MDA) concentration, and an increase in paraoxonase-1 (PON1), indicating an improvement in antioxidant function. Additionally, a sub-fraction of HDL-c was elevated, positively modulating expression of MCP-1 and VCAM-1, which is correlated with lower adhesion of monocytes. Considering these data, Sang and colleagues [11] concluded that aerobic training provides improvements in the anti-inflammatory capacity of subjects with MS, regardless of calorie restriction. Furthermore, the mechanism responsible for these actions appears to be connected to a higher PON1 activity, NO production and endothelium NOS (eNOS) expression.

The results of this review demonstrate that physical exercise provides several benefits to obese patients, independently of calorie restriction, confirming the importance of exercise in the prevention and treatment of chronic inflammation. It is important to emphasize that this review covers a single strategy of training, the aerobic exercise of moderate intensity. There are other possibilities, such as strength training. The search was restricted in order to select a higher amount of data based on the same strategy. The ability of aerobic training to positively 
modulate chronic inflammation, which is characteristic of obesity, is therefore evident.

\section{Acknowledgements}

The authors would like to thank Federal University of Health Sciences of Porto Alegre (UFCSPA), Coordination of Improvement of Higher Education Personnel (CAPES) and Foundation for Research Support of the State of Rio Grande do Sul (FAPERGS).

\section{References}

[1] WHO, Overweight and Obesity: Updated January 2015. http://www.who.int/mediacentre/factsheets/fs311/en/

[2] Swinburn, B.A., Sacks, G., Hall, K.D., McPherson, K., Finegood, D.T., Moodie, M.L. and Gortmaker, S.L. (2011) The Global Obesity Pandemic: Shaped by Global Drivers and Local Environments. Lancet, 378, 804-814. https://doi.org/10.1016/S0140-6736(11)60813-1

[3] Rodriguez-Hernandez, H., Simental-Mendia, L.E., Rodriguez-Ramirez, G. and Reyes-Romero M.A. (2013) Obesity and Inflammation: Epidemiology, Risk Factors, and Markers of Inflammation. International Journal of Endocrinology, 2013, Article ID: 678159. https://doi.org/10.1155/2013/678159

[4] Coelho, M., Oliveira, T. and Fernandes, R. (2013) Biochemistry of Adipose Tissue: An Endocrine Organ. Archives of Medical Science, 9, 191-200.

https://doi.org/10.5114/aoms.2013.33181

[5] Gomes, F., Telo, D.F., Souza, H.P., Nicolau, J.C., Halpern, A. and Serrano C.V. (2010) Obesity and Coronary Artery Disease: Role of Vascular Inflammation. Arquivos Brasileiros de Cardiologia, 94, 255-261, 273-279, 260-266.

[6] You, T., Arsenis, N.C., Disanzo, B.L. and Lamonte, M.J. (2013) Effects of Exercise Training on Chronic Inflammation in Obesity: Current Evidence and Potential Mechanisms. Sports Medicine, 43, 243-56.

https://doi.org/10.1007/s40279-013-0023-3

[7] Fiuza-Luces, C., Garatachea, N., Berger, N.A. and Lucia, A. (2013) Exercise Is the Real Polypill. Physiology, 28, 330-58. https://doi.org/10.1152/physiol.00019.2013

[8] Abd El-Kader, S., Gari, A. and Salah El-Den, A. (2013) Impact of Moderate versus Mild Aerobic Exercise Training on Inflammatory Cytokines in Obese Type 2 Diabetic Patients: A Randomized Clinical Trial. African Health Sciences, 13, 857-863. https://doi.org/10.4314/ahs.v13i4.1

[9] Ryan, A.S., Ge, S., Blumenthal, J.B., Serra, M.C., Prior, S.J. and Goldberg, A.P. (2014) Aerobic Exercise and Weight Loss Reduce Vascular Markers of Inflammation and Improve Insulin Sensitivity in Obese Women. Journal of the American Geriatrics Society, 62, 607-614. https://doi.org/10.1111/jgs.12749

[10] Ordonez, F.J., Rosety, M.A., Camacho, A., Rosety, I., Diaz, A.J., Fornieles, G., Garcia, N. and Rosety-Rodriguez, M. (2014) Aerobic Training Improved Low-Grade Inflammation in Obese Women with Intellectual Disability. Journal of Intellectual Disability Research, 58, 583-590. https://doi.org/10.1111/jir.12056

[11] Sang, H., Yao, S., Zhang, L., Li, X., Yang, N., Zhao, J., Zhao, L., Si, Y., Zhang, Y., Lv, X., Xue, Y. and Qin S. (2015) Walk-Run Training Improves the Anti-Inflammation Properties of High-Density Lipoprotein in Patients with Metabolic Syndrome. The Journal of Clinical Endocrinology and Metabolism, 100, 870-879. 
https://doi.org/10.1210/jc.2014-2979

[12] Trachta, P., Drapalova, J., Kavalkova, P., Touskova, V., Cinkajzlova, A., Lacinova, Z., Matoulek, M., Zelinka, T., Widimsky Jr., J., Mraz, M. and Haluzik, M. (2014) Three Months of Regular Aerobic Exercise in Patients with Obesity Improve Systemic Subclinical Inflammation without Major Influence on Blood Pressure and Endocrine Production of Subcutaneous Fat. Physiological Research/Academia Scientiarum Bohemoslovaca, 63, S299-S308.

[13] Donnelly, J.E., Blair, S.N., Jakicic, J.M., Manore, M.M., Rankin, J.W. and Smith, M.B.K. (2009) American College of Sports, American College of Sports Medicine Position Stand. Appropriate Physical Activity Intervention Strategies for Weight Loss and Prevention of Weight Regain for Adults. Medicine \& Science in Sports \& Exercise, 41, 459-471. https://doi.org/10.1249/MSS.0b013e3181949333

[14] Krause, M., Rodrigues-Krause, J., O’Hagan, C., Medlow, P., Davison, G., Susta, D., Boreham, C., Newsholme, P., O’Donnell, M., Murphy, C. and De Vito, G. (2014) The Effects of Aerobic Exercise Training at Two Different Intensities in Obesity and Type 2 Diabetes: Implications for Oxidative Stress, Low-Grade Inflammation and Nitric Oxide Production. European Journal of Applied Physiology, 114, 251-260. https://doi.org/10.1007/s00421-013-2769-6

[15] Wang, Z. and Nakayama, T. (2010) Inflammation, a Link between Obesity and Cardiovascular Disease. Mediators of Inflammation, 2010, Article ID: 535918.

Submit or recommend next manuscript to SCIRP and we will provide best service for you:

Accepting pre-submission inquiries through Email, Facebook, LinkedIn, Twitter, etc. A wide selection of journals (inclusive of 9 subjects, more than 200 journals)

Providing 24-hour high-quality service

User-friendly online submission system

Fair and swift peer-review system

Efficient typesetting and proofreading procedure

Display of the result of downloads and visits, as well as the number of cited articles

Maximum dissemination of your research work

Submit your manuscript at: http://papersubmission.scirp.org/

Or contact ojemd@scirp.org 